\title{
Hysterosalpingography (HSG), hysteroscopy and laparoscopic evaluation of female genital tract of patient attending tertiary infertility centre and correlation of various modalities
}

\author{
G. D. Maiti, Prasad Lele*
}

Department of Obstetrics and Gynecology, Command Hospital (EC), WBUHS, Kolkata, West Bengal, India

Received: 01 February 2018

Accepted: 07 March 2018

*Correspondence:

Dr. Prasad Lele,

E-mail: prasadlele@hotmail.com

Copyright: () the author(s), publisher and licensee Medip Academy. This is an open-access article distributed under the terms of the Creative Commons Attribution Non-Commercial License, which permits unrestricted non-commercial use, distribution, and reproduction in any medium, provided the original work is properly cited.

\begin{abstract}
Background: Hysterosalpingogarphy (HSG) has traditionally been the first line of investigation anatomy and contour of uterine cavity along with fallopian tube and its patency. Because of limitations of HSG, video endoscopic evaluation of endometrial and peritoneal cavity by diagnostic hysteroscopy and laparoscopy can diagnose many subtle and obvious pathologies in evaluation of infertile couple. To know this difference author studied the efficacy of HSG along with diagnostic laparohysteroscopy.

Methods: HSG, Diagnostic Hysteroscopy and Laparoscopy were performed on a group of 50 Patient of primary and secondary infertility. Findings of HSG, Hysteroscopy and Laparoscopy were computed, analyzed and corelated.

Results: HSG showed a false positive rate of $25 \%$ for tubal factor and false negative $12 \%$ for uterine factors when compared with hysteroscopic and laparoscopic findings. The sensitivity of HSG was $75 \%$ and specificity was $88 \%$ when compared with Hysteroscopic and Laparoscopic findings. Among various abnormality detected during the present study were, congenital anomaly 7(14\%), Asherman syndrome $5(10 \%)$, Tubal factor defect 6(12\%), fibroid $3(6 \%)$ and Pelvi-inflammatory disease in $7(14 \%)$ of cases.

Conclusions: Though HSG is a simple procedure for detecting abnormality of female genital tract, due to its low specificity and sensitivity hysterolaparoscopy should be complemented during infertility work up in all patient.
\end{abstract}

Keywords: HSG, Hysteroscopy, Laparoscopy

\section{INTRODUCTION}

Infertility is one of the most prevalent problems as a result of rapid urbanization and related family nuclearization associated with it. ${ }^{1}$ In the Indian population around 15 percent of couples around are deemed infertile. The magnitude of social implication of the problem is enormous for 125 billion total population of the country. The stigmatization it carries in India makes it a dreadful one. ${ }^{2}$
The investigation for an infertile couple should ideally start if they are unable to conceive after one year of cohabitation. This may be relaxed in elderly and some special situations. The basic workup while investigating the infertile couple after counseling along with history taking includes semen analysis, tests for ovulation and tests for tubal patency. ${ }^{3}$

Ruling out of congenital or acquired abnormality of the female genital organ remain the key procedure before formulating the treatment protocol of infertility patients. 
Hysterosalpingography (HSG) has been an important diagnostic tool in determining anatomical contour of uterine cavity as well as tubal anatomy and patency. It can detect the uterine malformation, synechae, fibroids distorting uterine cavity as well as patency of fallopian tube. As the delineation of complete genital system was not possible with HSG alone, laparoscope and hysterosocpe become complementary tools in complete work up of female genital tract. The limitation of HSG namely inability to read pelvic cavity, occurrence of tubal spasm could be overcome by addition of both hysterosocpe and laparoscope. ${ }^{4}$ Moreover, improved modern magnified videoendoscopic monitoring system accelerated detection of very early stage of pelviendometrio-tubal disease of female genital organ which has improved in treatment of infertility women to a definite extent. ${ }^{5}$

The present study was conducted to investigate the infertile female genital organ to diagnose pathologies with HSG, hysteroscope and laparoscope and to compare findings with different modalities.

\section{METHODS}

This study was conducted in a tertiary infertility center in public sector hospital. Fifty patients of infertility women attending the centre where included in the study.

\section{Inclusion criteria}

All patient with primary and secondary infertility.

\section{Exclusion criteria}

- Male factor infertility

- Surgical sterilization

- Endocrinal abnormality namely abnormal FSH, LH, serum prolactin, T3, T4, TSH

HSG was performed to all patient before taking up for diagnostic laparo-hysteroscopy. The HSG was done during postmenstrual period (D7 to D10 of the cycle). Three films were taken following introduction of contrast (conray 240). $4 \mathrm{~mm} \mathrm{30}$ ' telescope with $5 \mathrm{~mm}$ inner and 7 mm outer sheath hysteroscope of Karl Storz was used for Hysteroscopy and $10 \mathrm{~mm}$ 0' telescope was used for diagnostic laparoscopy. Single chip camera with color monitor, endoflator for pneumoperitoneum with $\mathrm{CO}_{2}$ and endomat for suction irrigation for both hysteroscopic and Laparoscopic procedure were used. Normal saline was used as distension fluid in diagnostic hysteroscope, 300watt xenon cold light source and videocassette recorder were used during procedure.

All patient undergoing diagnostic hysteron laparoscopy were listed during premenstrual period. The patient was put in semilithotomy position and all cases were done under general anaesthesia. After antiseptic and aseptic dressing and draping, examination under anaesthesia
(EUA) was done and findings were noted. Cervical canal was serially dilated up to $6 \mathrm{~mm}$ size metal dilator and the hysteroscope was slowly introduced through the external os of cervix under visualization on monitor. The irrigation channel was kept open to push jet of distension media on the way of introduction of hysteroscope making view clear. The irrigation fluid opens up the cervical canal and uterine cavity.

With vision on video monitor system hysteroscpe was introduced till fundus of uterine cavity is visible. The scope was rotated to each side to visualize both the ostea. After scanning through uterine walls and ostea, hysteroscope was gradually withdrawn to take final panoramic view of uterine cavity. All abnormal findings were noted and recorded. The evidence of septum, intra uterine adhesion, endometrial polyp, fibroid, abnormality in ostea namely pinpoint ostea, single ostea, fibrosis around ostea were noted. The shape and size of entire uterine cavity was ascertained on panoramic view. The hysteroscope was gradually withdrawn while scanning through internal os and cervical canal to complete the procedure of hysteroscopy.

Cervical manipulator was put on completion of Hysteroscopy and laparoscopic procedure was started. Sub-umbilical small vertical/ transverse incision was given and $11 \mathrm{~mm}$ trocar with cannuala was introduced directly into the abdominal cavity. The abdominal entry of cannula was confirmed by visualization of abdominal structure through laparoscope. Whenever there was unsuccessful direct trocar entry Verries needle was utilized for pneumoperitoneum. The cannula was attached to $\mathrm{CO}_{2}$ endoflator which was set at 11 to $15 \mathrm{~mm}$ $\mathrm{Hg}$ of intrabdominal pressure. The laparoscope was manipulated to get initial panoramic view of pelvic cavity.

The second puncture site was made on left iliac fossa to introduce palpation probe taking care of vessels. Scanning of pelvic cavity starts from visualizing right ovary, ovarian fossa, pouch of Douglas, utero-sacral ligaments, left ovarian fossa, left ovary. The uterus was scanned to look for any fibroid. Tubal size, shape and evidence of adhesion on external surface, were noted. The dye was introduced through cervical canal and spillage of dye through fimbrial end was noted. Sign of endometriosis PID, tubal pathology, fibroid etc. were noted. Finally, the laparoscope was rotated to see the liver bed for evidence of any perihepatic adhesion. Pneumodeflation and D and $\mathrm{C}$ were done to conclude the procedure. The endometrium was send for HPE and PCR for tuberculosis where indicated. Prophylactic antibiotic was given to every patient.

\section{RESULTS}

Fifty patients at the age group of 22-46 yrs were studied. The period of infertility was between 03-12 yrs. Thirtyfour cases were primary and 16 cases were secondary 
infertility. Out of 34 primary infertility (22-30 yrs) age group were maximum. 26 cases and 08 cases were more than 30 yrs of age. Amongst secondary infertility, both the age groups were equal i.e. 08 in each group. In $\leq 30$ yrs age group, menstrual abnormality in the form of oligo/ hypomenorrhoea, polymenorrhea were present in 13 cases and 07 cases in $>30$ yrs age group. Out of 07 cases who had abnormal pelvic examination findings in the form of restricted mobility, irregular bulky uterus etc, 03 were in the age group of $\leq 30$ and 04 were at the age group of $>30$ yrs (Figure 1).

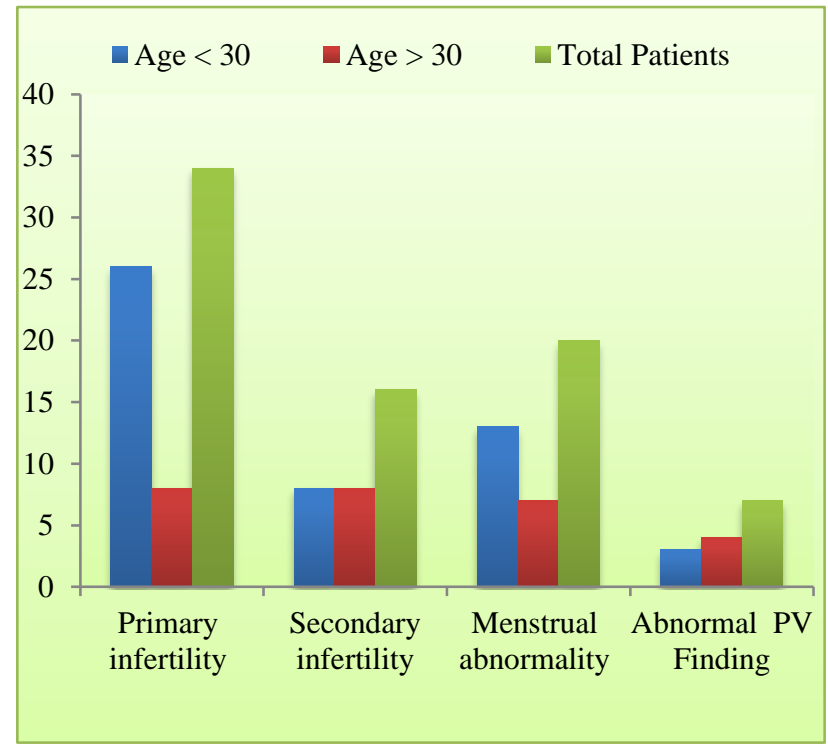

Figure 1: Clinical profile.

Prelaparohysteroscopic HSG findings which includes total 17 (34\%) of abnormal HSG findings and $33(66 \%)$ had normal findings. Abnormality detected to be $5(10 \%)$ Mullerian anomaly, 8(16\%) tubal block, 3(6\%) Asherman's syndrome and 1(2\%) fibroid uterus (Table 2).

Table 2: Abnormality on HSG $(n=50)$.

\begin{tabular}{|c|c|c|c|c|}
\hline \multirow[t]{2}{*}{ Abnormality } & \multicolumn{2}{|l|}{ Age } & \multirow{2}{*}{ Total } & \multirow{2}{*}{$\%$} \\
\hline & $\leq \mathbf{3 0}$ & $>\mathbf{3 0}$ & & \\
\hline $\begin{array}{l}\text { Congenital mulerian } \\
\text { anomaly }\end{array}$ & 04 & 01 & 05 & 10 \\
\hline Bicornuate/subseptate & 02 & 01 & 03 & \\
\hline Unicornuate & 01 & - & 01 & \\
\hline Hypoplastic & 01 & - & 01 & \\
\hline Asherman's & 02 & 01 & 03 & 06 \\
\hline Sumucous Fibroid & - & 01 & 01 & 02 \\
\hline Tubal defects & 06 & 02 & 08 & 16 \\
\hline Total & 12 & 05 & 17 & 34 \\
\hline
\end{tabular}

Hysteroscopic evaluation showed 22(44\%) had abnormal findings namely 7 (14\%) Mullerian abnormality, 5 (10\%) Asherman 's syndrome, 1(2\%) endometrial polyp, 2(4\%) submucous fibroid. Abnormal ostea depicting abnormal tubal function was detected in $05(10 \%)$ and other abnormality in 02 (4\%) of cases (Table 3$)$.

In laparoscopic findings were out of $04(08 \%)$ Mullerian anomaly diagnosed as septate / sub septate in histeroscopy turned out to be bicornuate in laparoscopy in another 02 cases, totalling 04 cases of bicornuate uterus. Other abnormal findings in laparoscopy includes $6(12 \%)$ pelvic endometriosis, 07 (14\%) PID, 03 (06\%) fibroid uterus and $06(12 \%)$ had negetive chromotubation (tubal block). 01 case had polycystic ovary (Table 4).

Table 3: Hysteroscopic abnormality $(n=50)$.

\begin{tabular}{|c|c|c|c|c|}
\hline Abnormality & Age & & Total & $\%$ \\
\hline $\begin{array}{l}\text { Mullerian } \\
\text { anomaly }\end{array}$ & 06 & 01 & 07 & 14 \\
\hline Bicornuate & 02 & 01 & & \\
\hline Unicornuate & 01 & - & & \\
\hline Subseptate & 01 & - & & \\
\hline Septate & 01 & - & & \\
\hline Hypoplastic & 01 & - & & \\
\hline Asherman & 03 & 02 & 05 & 10 \\
\hline $\begin{array}{l}\text { Endomaterial } \\
\text { abnormality }\end{array}$ & 01 & 02 & 03 & 06 \\
\hline Abnormal ostea & 05 & - & 05 & 10 \\
\hline Fibroid & - & 02 & 02 & 04 \\
\hline Total & 14 & 07 & 22 & 44 \\
\hline
\end{tabular}

Table 4: Abnormality on laparoscopy $(n=50)$.

\begin{tabular}{|lllll|}
\hline Abnormality & Age & \multicolumn{2}{c}{ Total } & $\%$ \\
\hline Mullerian anomaly & 06 & 01 & 07 & 14 \\
\hline Bicornuate & 03 & 01 & 04 & \\
\cline { 1 - 2 } Unicornuate & 01 & - & 01 & \\
Arcuate & 01 & - & 01 & \\
Hypoplastic & 01 & - & 01 & \\
\hline Endometriosis & 05 & 01 & 06 & 12 \\
\hline PID/Tubal adhesion & 06 & 01 & 07 & 14 \\
\hline Negative dye test & 04 & 02 & 06 & 12 \\
\hline Fibroid & - & 03 & 03 & 06 \\
\hline PCOD & 01 & - & 01 & \\
\hline Total & 22 & 08 & 30 & 58 \\
\hline
\end{tabular}

While correlating findings of different modalities which is depicted in Table 5, it can be observed that 02 congenital anomaly, 02 fibroid and 02 cases of Asherman was under diagnosed by HSG which has been picked up by histeroscopy.

Two cases of tubal block were over diagnosed by HSG but ruled out by laparoscopy by positive chrotubation during the procedure. Total 06 pathology by hysteroscope and 13 abnormalities were detected by laparoscope which has been missed by HSG also 06 abnormalities of uterine factor were detected by histeroscopy where HSG had normal report. 
Table 5: Correlation of HSG, hysteroscope and laparoscope $(\mathbf{n}=\mathbf{5 0})$.

\begin{tabular}{|c|c|c|c|}
\hline Findings & HSG & Hysteroscope & Laparoscope \\
\hline $\begin{array}{l}\text { Mullerian } \\
\text { anomally }\end{array}$ & 05 & 07 & 07 \\
\hline Asherman & 03 & 05 & - \\
\hline $\begin{array}{l}\text { Tubal factor } \\
\text { defect }\end{array}$ & 08 & $\begin{array}{l}05 \text { (abnormal } \\
\text { ostea) }\end{array}$ & 06 \\
\hline Fiborid & 01 & 03 & 03 \\
\hline Endometriosis & - & - & 06 \\
\hline $\begin{array}{l}\text { PID/tubal } \\
\text { adhesion }\end{array}$ & - & $\begin{array}{l}05 \text { (abnormal } \\
\text { ostea) }\end{array}$ & 07 \\
\hline PCOD & - & $\begin{array}{l}01 \text { (thick } \\
\text { endmetrium) }\end{array}$ & 01 \\
\hline
\end{tabular}

Hence, false negative for HSG (12\%) and specificity (88\%), 08 cases of tubal block were diagnosed by HSG out of which 2 had been ruled out by laparoscopy. False positive for HSG $(24.99 \%) \sim ~ 25$; sensitivity $(75 \%)$.

\section{DISCUSSION}

HSG is a modality of a century old, still has its relevance in modern era of computerized and sophisticated investigative modalities. The HSG can give the initial overview of female genital organ while investigating an infertile woman. Despite the relative simplicity, HSG leads to incorrect interpretation either false positive or false negative. The most problem is due to cornual block due to myometrial spasm. ${ }^{4}$ The relative role of HSG and hysteroscopy in evaluating the uterus in infertility has long been debated. According to a review of 12 series, $10-62 \%$ cases had abnormal hysteroscopic findings in women where HSG had a normal report. ${ }^{5}$ On the contrary, results reported on HSG are not confirmed by hysteroscopy. ${ }^{6}$ In one study 324 women reported for IVF, 152 underwent hysteroscopy because of abnormal HSG. Hysteroscopy showed intrauterine pathology in 50\% cases, intrauterine adhesion being the commonest. HSG had low specificity (23\%), false positive rate of $44 \%$ and false negative rate of $10 \% .^{7}$ Many other investigations have suggested a negative predictive value of HSG ranging from $57-92 \%$ and positive predictive value from $30-84 \% .^{5}$ In the present study, sensitivity of HSG was $75 \%$ and specificity was $88 \%$ for endometrial and tubal pathology when compared with hysteroscopic and laparoscopic findings respectively.

Out of 50 cases investigated, HSG revealed 17 (34\%) abnormality, which is compatible with the results of Otubu JA et al and Snowden et al. ${ }^{8,9}$ Congenital anomaly is seen in $5(10 \%)$ of cases which is near to findings of Makiano $\mathrm{T}$ et al in Japanese population at high risk which was $14.7 \% .^{10}$ Maheux-Lacroix $S$ et al in their metaanalysis on subfertile woman concluded that HSG has a limited value in determining tubal patency because of low sensitivity but it is useful for ruling out tubal obstruction because of high specificity. ${ }^{11}$ The incidence of Asherman in the present study was $03(06 \%)$ by HSG but $05(10 \%)$ by hysteroscope. This may be due to overfilled uterus missing the HSG findings.

Due to high rate of erroneous interpretation of HSG, laparoscope is employed to verify either positive or negative result, mainly tubal and pelvi-peritoneal factors. In current study, 06 (12\%) endometriosis, 07 (14\%) pelvic adhesion was detected by diagnostic laparoscopy which could not have been detected either by HSG nor by hysteroscopy.

So, valid question arises that weather is it worthwhile to subject all infertile women to undergo pre laporoscopy HSG.? In past few years the technique of hysteroscopy has evolved as an alternative to HSG particularly when combined hysteroscopy, laparoscopy and injection of dye to test tubal patency are done. In some study, uterine pathology was detected in $39 \%$ where HSG was showing normal report. ${ }^{12}$

In the present study, all cases of abnormal HSG has been detected by laparo-hysteroscopy. More over hysterolaparoscopy has revealed more and more pathology which has been reported as normal by HSG. Nonavailability of hystero-laparoscope is the major drawback regarding non-performance of this modality in all units but if the equipment's are available and gynaecologist is skilled in its use, the combination of HSG and hysterolaparoscopy would be an ideal modality in working up infertile lady. ${ }^{13}$

\section{Funding: No funding sources \\ Conflict of interest: None declared \\ Ethical approval: Not required}

\section{REFERENCES}

1. White MJ, Muhidin S, Andrzejewaki C, Tagoe E, Knight R, Reed H. Urbanization and Fertility: An Event-History Analysis of Coastal Ghana. Demography. 2008;45(4):803-16.

2. Sarkar S, Gupta P. Socio-Demographic Correlates of Women's Infertility and Treatment Seeking Behavior in India. J Reprod Infertil. 2016;17(2):123-32.

3. Kamel RM. Management of the infertile couple: an evidence-based protocol. Reprod Biol Endocrinology : RB\&E. 2010;8:21.

4. Phillips $\mathrm{CH}$, Benson CB, Ginsburg ES, Frates MC. Comparison of uterine and tubal pathology identified by transvaginal sonography, hysterosalpingography, and hysteroscopy in female patients with infertility. Fertil Res Pract. 2015 Dec 23;1:20.

5. Comparative Prospective Study of Hysterosalpingography and Hysteroscopy in Infertile Women Leena Wadhwa, Pooja Rani, Pushpa Bhatia J Hum Reprod Sci. 2017 Apr-Jun;10(2):73-8.

6. Maheux-Lacroix S, Boutin A, Moore L, Bergeron ME, Bujold E, Laberge P, Lemyre M, Dodin S. Hysterosalpingosonography for diagnosing tubal occlusion in subfertile women: a systematic review 
with meta-analysis. Hum Reprod. 2014 May;29(5):953-63.

7. Ngowa JDK, Kasia JM, Georges Ng-T, Nkongo V, Sone C, Fongang E. Comparison of hysterosalpingograms with laparoscopy in the diagnostic of tubal factor of female infertility at the Yaoundé General Hospital, Cameroon. Pan Afr Med J. 2015;22:264.

8. Otubu JA, Sagay AS, Dauda S. Hysterosalpingogram, laparoscopy and hysteroscopy in the assessment of the infertile Nigerian female. East Afr Med J. 1990 May;67(5):370-2.

9. Snowden EU, Jarrett JC 2nd, Dawood MY. Comparison of diagnostic accuracy of laparoscopy, hysteroscopy, and hysterosalpingography in evaluation of female infertility. Fertil Steril. 1984 May;41(5):709-13.

10. Makino T, Hara T, Oka C, Toyoshima K, Sugi T, Iwasaki K, Umeuchi M, Iizuka R. Survey of 1120 Japanese women with a history of recurrent spontaneous abortions. Eur J Obstet Gynecol Reprod Biol. 1992 Apr 21;44(2):123-30.
11. Maheux-Lacroix S, Boutin A, Moore L, Bergeron ME, Bujold E, Laberge P, Lemyre M, Dodin S. Hysterosalpingosonography for diagnosing tubal occlusion in subfertile women: a systematic review with meta-analysis. Hum Reprod. 2014 May;29(5):953-63.

12. Nigam A, Saxena P, Mishra A. Comparison of Hysterosalpingography and Combined Laparohysteroscopy for the Evaluation of Primary Infertility. KUMJ. 2015 Oct-Dec;13(52):281-5.

13. Vaid K, Mehra S, Verma M, Jain S, Sharma A, Bhaskaran S. Pan Endoscopic Approach "Hysterolaparoscopy" as an Initial Procedure in Selected Infertile Women. JCDR. 2014;8(2):95-98.

Cite this article as: Maiti GD, Lele P.

Hysterosalpingography (HSG), hysteroscopy and laparoscopic evaluation of female genital tract of patient attending tertiary infertility centre and correlation of various modalities. Int J Reprod Contracept Obstet Gynecol 2018;7:1597-601. 